\title{
Screening in rheumatology: the impact on the everyday experience of patients in the Brazilian public health system
}

Varlei Antonoio Serratto ( $\nabla$ varleiserratto@yahoo.com.br)

Prefeitura Municipal de Curitiba

Dora Pedroso Kowacs

Universidade Positivo

Sérgio Candido Kowalski

Univerisdade Federal do Paraná

\section{Research Article}

Keywords: Medical Teletriage, Rheumatology, Public healthcare, Patient Care, Referral and Consultation

Posted Date: September 30th, 2021

DOl: https://doi.org/10.21203/rs.3.rs-891852/v1

License: (1) This work is licensed under a Creative Commons Attribution 4.0 International License.

Read Full License 


\section{Abstract \\ Background}

In recent years, due to the increased incidence of rheumatologic diseases, the demand for consultations in rheumatology has risen. In the Brazilian public health system, patients with rheumatologic complaints are referred from primary care to specialized consultation, and must wait in a waiting list for the specialized care. In 2015, the waiting time for the first consultation in rheumatology, in Curitiba- Brazil, was 600 days. In attempt to reduce this time, in-person and remote screening was implemented that same year in a healthcare service in Curitiba. From 2015 to 2019 the variation in the number of patients in waiting lists for their first rheumatology consultation and the length of the waiting period for their first referral was evaluated.

\section{Methods}

Observational study in a time series. The patients in the study were referred to a primary healthcare center for an assessment of rheumatology in Curitiba, Brazil. The data was analyzed based on the first consultation with the rheumatologist. The variables were the number of patients in the waiting list and the waiting period for the appointment with the doctor. The research was carried out through a computerized system called " $e$-saude" [electronic health] runed by the Health Secretary of the Municipality of Curitiba. A comparison was made between the period of 2013-2015, in a model for treatment without screening, and 2015-2019, when the in-person and remote screening first began.

\section{Results}

Between 2015 and 2019 there was a reduction in the waiting list of 6,429 patients to 25 patients, while there was an average of 56.5 patients in the last two years;. With regard to the waiting period for the first appointment with the rheumatologist in 2019, there was a reduction of 600 days to a minimum of 4 days and a maximum of 52 days.

\section{Conclusion}

Both in-person and remote screening for asynchronous electronic consultations for rheumatologist in Curitiba led to a reduction in the waiting time and number of patients for the first appointment with the rheumatologist, proving to be a useful method for reducing the time and number of patients in the waiting list for a specialized consultation.

\section{Background}


Studies have shown that the pevailing incidence of rheumatic diseases such as arthritis among the public have increased by 3\%. Despite this, the interest of doctors in specialist rheumatology has been declining. This imbalance is likely to be reflected in the offer and demand for consultations in this specialist area where there is an aging population and the treatment of rheumatic diseases (such as arthritis) is characterized by an ever-increasing complexity $(1,22,33)$.

At the same time, the early diagnosis and treatment of patients with rheumatic diseases such as arthritis, has become an increasingly important type of medical practice in an attempt to achieve the therapeutic goals of a wide range of diseases. In seeking to attain the therapeutic goals established for the low remission or activity of the disease, there must be mechanisms in place that allow a reduction of the waiting time experienced by the patient before the appointment with the rheumatologist doctor.

The reduction of the waiting time not only ensures a fair treatment of various rheumatic diseases but also has the effect of enabling a larger number of patients to attain the established therapeutical goals $(23,24,35,36)$.

When employing strategies for the reduction of the waiting period experienced by the patients, there are several devices that allow an early diagnosis of arthritis that have proved to be very effective for use in primary healthcare. Tools such as CARE for the early diagnosis of arthritis have been designed for this purpose ${ }^{(3)}$. Models for providing faster access to the rheumatologist are also a key factor in this procedure and are being employed in Brazil and throughout the world. These have led to a significant reduction in the waiting time for the first appointment with the rheumatologist and thus greatly increased the likelihood of an early diagnosis. As a result, doctors are able to attain the therapeutic goals, which have been laid down by a wide range of guidelines in rheumatology and guidance material from the World Health Organization ${ }^{(30)}$.

Our city of Curitiba, in the South of Brazil, has a population of approximately two million inhabitants and belongs to the Brazilian universal healthcare program known as "Sistema Único de Saúde" (SUS). It was faced with the challenge of reducing the waiting period of the patients because the list of people waiting for their first appointment with a rheumatologist had been increasing every year. In 2015 , the number of patients in the waiting list had reached 6000 and, on average, they had to wait 600 days for their first appointment (Graph 1 and Table 1).

In this article we discuss the screening model for rheumatology employed for primary healthcare patients during their first appointment with the rheumatologist in the municipality of Curitiba - in the Brazilian Public Healthcare Program (SUS). This reflected the change in the waiting period of the patients following the introduction of the in-person and remote screening model by the asynchronous electronic consultation.

\section{OBJECTIVE}


To estimate the variation in the number of patients in the waiting list as well as the length of the waiting period for the first appointment with the rheumatologist, after the introduction of in-person and remote screening by the asynchronous electronic consultation in the municipality of Curitiba.

\section{Methodology}

The study received the approval of the Research Ethics Committee under report number 2.958.260 CAAE 95430618.1.0000.0101 - it was an observational study carried out in a time series (in the period from April 2015 to December 2019).

In April 2015, a screening center was set up for rheumatology outpatients, together with a rheumatologist who was responsible for assessing patients in a waiting list for their first consultation, regardless of the complaint. Patients came from these healthcare clinics for an assessment with a specialist. After several months had elapsed, the work schedule of the screening doctor who handled the return visits was altered so that he only treated patients from this waiting list for the first consultation. The patients of this rheumatologist, who may have already been monitored for the treatment of chronic diseaes, were transferred to other services provided by the municipality and thus left him with the sole task of screening the list of patients waiting for their first appointment.

In January 2017, another rheumatologist doctor was appointed to the outpatients screening clinic, which remained wholly devoted to the in-person screening of patients in this same waiting list.

In September 2017 - through the mediation of the Health Services Department (DAS) of the Health Secretary of the municipality of Curitiba - an electronic consultation was set up which was dubbed the "teleconsultant in rheumatology". This entailed allowing the rheumatologist screening doctors to assess the complaints described by the general practitioners in the clinics of the patients from the Brazilian Public Health Program, through a computerized system based on a register of health records. From this time onwards, the patients underwent screening by means of asynchronous electronic screening or teleconsultation. In addition, depending on the assessment of the rheumatologist doctor/teleconsultant, the patient was either sent to a screening service for an in-person examination or was referred to a service provider for monitoring his/her disease if this had already been diagnosed.

By means of the eletronic telemedicine platform for remote consultation, it was possible to analyze the data that had led to the referral. If there were any queries or uncertainties about the clinical case study, we could add information from laboratory and radiological research and request the doctors from the Health Program for more clinical data if necessary. It was always in the form of an asynchronous virtual care platform.

This electronic system for remote assessment, called "e-saude", was designed by the city council itself, where access can be obtained to the patients' medical records in any part of the city. This means not only having access to the traditional clinical services of the Public Health Program but also to the clinical consultations in other specialist areas. Access can also be obtained to the results of laboratory tests and 
images, as well as the medical assessments from radiological tests such as those based on radiography and tomography.

This computerized system allows not only access to health records (as described above) but also enables people to consult a large amount of data made available through the public health records of the municipality of Curitiba, for the scrutiny and analytical research of various public health indices. The demand for a wide range of specialist services, including rheumatology, can be monitored by means of these reports and Excel spreadsheets. They allow research into a wide range of variables that are conducted on a monthly basis and in a systematic way, such as the average waiting period, the number of patients in the waiting list and the offer of appointments for the first consultation. This can assist in the establishment of a timely flow, the contracting of new services and the expansion of capacity.

In our study, an analysis was conducted of the data concerning the first consultation with the rheumatologist in the period from April 2005 to December 2019. The variables studied were the number of patients in the waiting list, the length of the waiting period, and the cost of a consultation with the rheumatologist. The sources for the analysis can be found in the "e-saude" database (central marking of the template, page 5 and 7, report 28,29 and 41 ) in the digital file on the following electronic address: esaude.curitiba.pr.gov.br/relatorios, whose access is restricted to professionals who work in the city's public health system. Data from the number of patients in the waiting list were collated. The waiting period for the first consultation, month by month between January 2013 and April 2015, and the results were compared with those obtained in the period from April 2015 to December 2019 (Table 1), after the screening by the rheumatologist had begun in April 2015 and the introduction of screening by the teleconsultant in rheumatology in September 2017.

It should be noted that during this period there were no changes in the number of rheumatologist doctors for in-person screening or for the teleconsultation. Moreover, there was no increase in the number of appointments offered for the first consultation by the rheumatology services.

The patients who had been screened and showed autoimmune inflammation symptoms, made appointments for subsequent consultations with the rheumatologist.

In addition, training courses were carried out to qualify doctors for primary healthcare in the years 2018 and 2019. These were designed to teach them how to recognize the warning signs of inflammatory diseases such as articular inflammation (flushing, heat, erythema and loss of articular cartilage), morning pain, and morning stiffness lasting more than one hour. Among the laboratory tests that revealed a probable immune-mediated disorder, such as a complete blood count, speed of the erythrocyte sedimentation rate, reactive, Protein $\mathrm{C}$ creatinphosphokinase, rheumatoid factor, antinuclear antibodies, extractable nuclear antigen (ENA) profile, supplements and partial urine sample, among other factors employed in the screening. If no suspect of autoimmune disease, such as fibromyalgia and primary arthritis, the patient was sent back with written referrals to the general medical clinics of primary healthcare. 
Whether the screening was conducted in-person or remote (through a teleconsultation), the clinical and laboratory data, which revealed symptoms of chronic inflammation, were assessed. If there was any uncertainty, supplementary tests could be requested from screening doctors by means of the "e-saude" system. An appointment could be made for a second in-person or remote visit by the rheumatologist himself to examine the patient again and thus determine if he should carry on with the rheumatology or continue with the treatment provided by the public healthcare program.

Because of this new model, after August 2018, it was possible to set up two screening clinics called "Rapid Access Clinics", where patients could be examined in loco, and outpatient screening could continue before the patients were formerly referred to the rheumatology services. At the same time, this was a flexible and speedy way of meeting the needs of the Primary Healthcare doctors when assessing which patients required an in-person examination with the rheumatologist before being formally referred to the rheumatology services for a further diagnosis or treatment. Figure 1 shows the path of the patient in the health service for a rheumatology assessment.

The data collected was compiled in tables and graphs so that a comparison could be made from the progressive reduction in the length of the waiting period and the number of patients.

\section{Results}

Between April 2015 and December 2019, there was a reduction in the waiting list of 6,429 patients (Figure 2) to 25 patients (average of 56.5 patients in the last 2 years - Figure 3). A reduction of 600 for a minimum of 4 days and a maximum of 52 days (average of 21 days) of waiting time for the first consultation with the rheumatologist in the last 2 years (Figure 4).

Figure 2 shows the values regarding the waiting time for the first consultation in rheumatology before the introduction of the screening system, while in the case of Figure 4, the values shown are after its introduction. It should be noted that in the first graph (Figure 2) the values increased, whereas in the second (Figure 4) they declined. The waiting time for the first appointment with the rheumatologist increased during the period where there was no screening model (Figure 2) and fell after this was introduced (Figure 4).

The number of appointments offered for the first consultation fluctuated during the period of the entire study but tended to decline during the period of study, even when new rheumatologists were contracted (Figure 5).

Figure 6 illustrates the sharp reduction in the number of patients for the first consultation after the introduction of both the in-person and remote screening model.

It can be seen in Table 1 that there is a reduction in both the waiting periods and the number of patients between April 2015 and December 2019. This ranged from 611 days and 6,429 patients to 25 
days and 73 patients with an average period of 28 waiting days and an average of 56.5 patients in the waiting list in the last 2 years.

\section{Discussion}

Both the in-person and remote rheumatology screening by the asynchronous electronic consultation in rheumatology succeeded in reducing the waiting time, as well as the number of patients in the waiting list for the first appointment with the specialist in the public health service of the Healthcare Program in the city of Curitiba.

Throughout the world, there is a concern about reducing the waiting time for the first consultation with a rheumatologist. University rheumatology services have relied on in-person or remote screening models to improve the prospects of a correct diagnosis and provide treatment as early as possible $e^{(4,5,6,7,8,9,10,11,12,16,31)}$.

Smole, et $a{ }^{(4)}$, made use of service models which employed in-person screening, and reduced the waiting time for the first appointment with the rheumatologist from months to weeks, or even days. Moreover, with regard to in-person screening, West et $a{ }^{(2)}$ conducted an analysis with almost a thousand patients in which only 4 patients remained without a diagnosis of their immune-mediated rheumatic diseases. Owing to the new dynamic features of the screening model (which also effectively allowed a new assessment to be made much earlier), they were able to review the signs of disease and symptoms of the patients and thus provide the due continuity required for the treatment $(1,2,3,4)$.

One of the benefits of screening is that it can enable a new assessment to be made of the patient quickly when an inflammatory disease may not have been detected.

Our study resembles the study undertaken by Hazlewood et $a^{(1)}$, in Canada, where remote screening was employed (such as an asynchronous electronic consultation) to reduce the waiting time for the first appointment with the rheumatologist. In addition, it could assist the in loco Primary Healthcare system in cases that could be followed up by initial treatment.

The benefíts of screening, such as those witnessed in the studies by Smolen et al and Hazlewood et al (whether in person or remote by an asynchronous electronic consultation) are going to meet the requirements of the guidelines for the treatment of various inflammatory rheumatic diseases. In the case of rheumatoid arthritis, studies such as those of Optima ${ }^{(23)}$, Prize ${ }^{(24)}$, Select Compare and Early ${ }^{(35)}$ provide evidence that the earlier treatment is begun for rheumatoid arthritis, the greater the benefits that can be given to the patients, such as attaining therapeutic goals earlier - this should certainly lead to less joint damage in the future.

One of the essential features for the success of the treatment is closely related to the time made available for the diagnosis and beginning of the treatment. This is often referred to in the study by TARA ${ }^{(32)}$ who 
makes clear that the patient should be examined and treated early to ensure less exposure and that this should include a rational use of immunosuppressant medication and thus the possibility of tapering.

The early arrival of patients at the clinic of the rheumatologist is a key aspect of their treatment. The time factor should be the clinical rationale of the rheumatologist doctor that can allow him to attain the best therapeutic results in the treatment of arthritis and this should not just depend on the choice of medication for the treatment. A patient diagnosed with 3 months of rheumatoid arthritis can achieve his therapeutic goals with upadacitinib in 4 weeks of treatment. In the case of patients with rheumatoid arthritis who may have by chance begun the same treatment with upadacitinib only 26 weeks after their diagnosis, the number who succeeded in reaching their therapeutic goals is less in the whole follow-up period of their treatment. It remains clear that early treatment is essential for an even better outcome during the treatment of rheumatoid arthritis $(35,36)$.

With regard to SUS, in the situation in Brazil, the challenges are even greater if one is concerned with reducing the waiting time of the patients and hence regarding the use of time as the best strategy for the treatment of rheumatoid arthritis. In our municipality of Curitiba, in the past, it took an average of 2 years to wait for the first visit to the rheumatologist but with the new screening model, we are able to reduce the waiting time for this appointment. Moreover, we are now in a position to include the time at the beginning of the disease as a key factor in the clinical decision-making for an improved treatment of rheumatoid arthritis, when on earlier occasions it was not possible.

However, there are limitations in thus study, which it is expected can be overcome in future research projects. The first limitation when dealing with public health in a city of almost 2 million inhabitants is the question of reproducibility; this is because it has some particular features (such as a computerized system of patient records) which few other cities in Brazil possess. The second factor is that we do not make use of a control group but prefer to compare our system with the previous service model, which did not employ any screening. It is now clear that from now on screening will be a factor that can assist in reducing the waiting period of the patients. Without doubt, a study carried out over a longer period of time would give a greater degree of robustness to the data obtained and as such, could become a support tool in public health for the reduction of waiting lists and waiting times for rheumatology treatment.

\section{Conclusion}

Based on the results, it can be concluded that rheumatological screening - whether in-person or remote by the asynchronous elecronic consultation in the public health system of the city of Curitiba, has been a key factor in mitigating the problem of the waiting period for patients in our city. This screening might offer a tool in public health for the reduction of waiting lists and the number of patients waiting for their first appointment with a rheumatologist doctor.

\section{Abbreviations}


SUS- Sistema Único de Saúde- Brazilian Public Health System

DAS- Health Services Department

ENA- extractable nuclear antigen

\section{Declarations}

\section{Ethics approval and consent to participate}

This study was approved by the Research Ethics Committee of Curitiba's Municipal Secretary of Health under report number 2.958.260 CAAE 95430618.1.0000.0101.

\section{Availability of data and materials' statement}

The datasets analysed during the current study are found on esaude.curitiba.pr.gov.br/relatorios (central marking of the template, page 5 and 7, report 28, 29 and 41) but are not publicly accessible due medical confidentiality, although are available from the corresponding author on reasonable request.

Competing interests

The authors declare that they have no competing interests.

\section{Funding}

The authors declare that there are no sources of funding for the research.

\section{Authros contributions}

VAS and SCK designed and directed the project. VAS wrote the manuscript with support from SCK and DPK. SCK helped supervise the project. VAS conceived the original idea. All authors discussed the results and contributed to the final manuscript.

\section{Acknowledgements}

We would like to thank Dra. Renata Machado Volpato Fernandes da Silva for the support and assistance on the outpatients screening clinic and Mrs. Frank Hanson for the assistance on translating the article.

\section{References}

1- Hazlewood GS, Barr SG, Lopatina E, Marshall DA, Lupton TL, Fritzler MJ, et al.. Improving Appropriate Access to Care With Central Referral and Triage in Rheumatology. Arthritis Care Res (Hoboken). 2016;68(10):1547-53. 
2- West SG, Pearson DW, Striebich CC, Goecker R, Kolfenbach JR. The Effect of pre-appointment consultation triage on patient selection and revenue generetion in a Universaty Rheumatology pratice. Arthritis Care Res (Hoboken). 2019;71(5):689-93.

3- Ten Brinck RM, van Dijk BT, van Steenbergen HW, le Cessie S, Numans ME, Hider SL, et al. Development nd validation of a clinical rule for recognition of early inflammatory arthritis. BMJ Open. 2019;8(11):1-10.

4- Smolen JS, Aletaha D, Barton A, Burmester GR, Emery P, Firestein GS, Kavanaugh A, McInnes IB, Solomon DH, Strand V, Yamamoto K. Rheumatoid arthritis. Nat Rev Dis Primers. 2018;4:1.

5- Nell VPK, Machold KP, Eberl G, Stamm TA, Uffmann M, Smolen JS. Benefit of very early referral and very early therapy with disease-modifying anti-rheumatic drugs in patients with early rheumatoid arthritis. 2004;43(7):906-14.

6- Maddison P, Jones J, Breslin A, Barton C, Fleur J, Lewis R, et al. Improved access and targeting of musculoskeletal services in northwest Wales: targeted early access to musculoskeletal services (TEAMS) programme. BMJ. 2004 Dec 4;329(7478):1325-7.

7- Harrington JT, Walsh MB. Pre-appointment management of new patient referrals in rheumatology: a key strategy for improving health care delivery. Arthritis Rheum. 2001 Jun;45(3):295-300.

8- Battafarano DF, Ditmyer M, Bolster MB, Fitzgerald JD, Deal C, Bass AR, et al . 2015 American College of Rheumatology Workforce Study: Supply and Demand Projections of Adult Rheumatology Workforce, 2015-2030. Arthritis Care Res (Hoboken). 2018 Apr;70(4):617-26.

9- Van Der Linden MPM, Le Cessie S, Raza K, Van Der Woude D, Knevel R, Huizinga TWJ, et al. Long-term impact of delay in assessment of patients with early arthritis. Arthritis Rheum. 2010;62(12):3537-46.

10- Newman ED, Harrington TM, Olenginski TP, Perruquet JL, McKinley K. "The Rheumatologist Can See You Now": Successful Implementation of an Advanced Access Model in a Rheumatology Practice. Arthritis Care Res. 2004;51(2):253-7.

11- Fitzgerald A, De Coster C, McMillan S, Naden R, Armstrong F, Barber A, et al. Relative urgency for referral from primary care to rheumatologists: The priority referral score. Arthritis Care Res. 2011;63(2):231-9.

12- Carpenter T, Katz SJ. Review of a rheumatology triage system: Simple, accurate, and effective. Clin Rheumatol. 2014;33(2):247-52.

13- Thompson AE, Haig SL, LeRiche NGH, Rohekar G, Rohekar S, Pope JE. Comprehensive arthritis referral study - Phase 2: Analysis of the comprehensive arthritis referral tool. J Rheumatol. 2014;41(10):1980-9.

14- Hazlewood GS, Barr SG, Lopatina E, Marshall DA, Lupton TL, Fritzler MJ, Mosher DP, Steber WA, Martin L. Improving Appropriate Access to Care With Central Referral and Triage in Rheumatology. 
Arthritis Care Res (Hoboken). 2016 Oct;68(10):1547-53.

15- Stainkey LA, Seidl IA, Johnson AJ, Tulloch GE, Pain T. The challenge of long waiting lists: how we implemented a GP referral system for non-urgent specialist' appointments at an Australian public hospital. BMC Health Serv Res. 2010 Nov 4;10:303.

16- Graydon SL, Thompson AE. Triage of referrals to an outpatient rheumatology clinic: analysis of referral information and triage. J Rheumatol. 2008 Jul;35(7):1378-83.

17- Gormley GJ, Steele WK, Gilliland A, Leggett P, Wright GD, Bell AL, et al. Can diagnostic triage by general practitioners or rheumatology nurses improve the positive predictive value of referrals to early arthritis clinics? Rheumatology. 2003;42(6):763-8.

18- Wickersham P, Golz D, West SG. Clinical academic rheumatology: Getting more than you pay for. Arthritis Care Res. 2005;53(2):149-54.

Landewé, RBM. Overdiagnosis and overtreatment in rheumatology: a little caution is in order. Ann Rheum Dis. 2018 Oct;77(10):1394-1396. doi: 10.1136/annrheumdis-2018-213700. Epub 2018 Jul 4.

19- Bergstra SA, Branco JC, Vega-Morales D, Salomon-Escoto K, Govind N, Allaart CF, et al. Inequity in access to bDMARD care and how it influences disease outcomes across countries worldwide: Results from the METEOR-registry. Ann Rheum Dis. 2018;1413-20.

20- Emery P, Burmester GR, Naredo E, Zhou Y, Hojnik M, Conaghan PG. Design of a phase IV randomised, double-blind, placebo-controlled trial assessing the ImPact of Residual Inflammation Detected via Imaging TEchniques, Drug Levels and Patient Characteristics on the Outcome of Dose Taper Ing of Adalimumab in Clinical Remission Rheumatoid ArThritis (RA) patients (PREDICTRA). BMJ Open. 2018;8(2):1-10.

21- Aletaha D, Maa JF, Chen S, Park SH, Nicholls D, Florentinus S, Furtner D, Smolen JS. Effect of disease duration and prior disease-modifying antirheumatic drug use on treatment outcomes in patients with rheumatoid arthritis. Ann Rheum Dis. 2019 Dec;78(12):1609-1615.

22- Myasoedova E, Davis J, Matteson EL, Crowson CS. Is the epidemiology of rheumatoid arthritis changing? Results from a population-based incidence study, 1985-2014. Ann Rheum Dis. 2020;79(4):440-4.

23- Kavanaugh A, Fleischmann RM, Emery P, Kupper H, Redden L, Guerette B, Santra S, Smolen JS. Clinical, functional and radiographic consequences of achieving stable low disease activity and remission with adalimumab plus methotrexate or methotrexate alone in early rheumatoid arthritis: 26week results from the randomised, controlled OPTIMA study. Ann Rheum Dis. 2013 Jan;72(1):64-71

24- hang W, Bansback N, Sun H, Pedersen R, Kotak S, Anis AH. Estimating the monetary value of the annual productivity gained in patients with early rheumatoid arthritis receiving etanercept plus 
methotrexate: Interim results from the PRIZE study. RMD Open. 2015;1(1):1-10.

25- van Mulligen E, de Jong PHP, Kuijper TM, van der Ven M, Appels C, Bijkerk C, Harbers JB, de Man Y, Molenaar THE, Tchetverikov I, Goekoop-Ruiterman YPM, van Zeben J, Hazes JMW, Weel AEAM, Luime JJ. Gradual tapering TNF inhibitors versus conventional synthetic DMARDs after achieving controlled disease in patients with rheumatoid arthritis: first-year results of the randomised controlled TARA study. Ann Rheum Dis. 2019 Jun;78(6):746-753.

26- Hilliquin S, Hugues B, Mitrovic S, Gossec L, Fautrel B, Louis IP. Ability of disease-modifying antirheumatic drugs to prevent or delay rheumatoid arthritis onset: a systematic literature review and meta-analysis. 2018;1-8.

27-Smolen JS, Emery P, Fleischmann R, et al. Adjustment of therapy in rheumatoid arthritis on the basis of achievement of stable low disease activity with adalimumab plus methotrexate or methotrexate alone: the randomised controlled OPTIMA trial. Lancet. 2014 Jan;383(9914):321-332.

28- Raval AD, Vyas A. Trends in Healthcare Expenditures among Individuals with Arthritis in the United States from 2008 to 2014. J Rheumatol. 2018 May;45(5):705-716

29- Demografia Médica no Brasil 2018. https://portal.cfm.org.br/index.php?

option=com_content\&view=article\&id=27509:2018-03-21-19-29-36\&catid=3

30- WHO, The World Medicines Situation 2011, Rational Use of medicines, 2011, https://www.who.int/medicines/areas/policy/world_medicines_situation.

31-Liddy C, Moroz I, Mihan A, Nawar N, Keely E. A Systematic Review of Asynchronous, Provider-toProvider, Electronic Consultation Services to Improve Access to Specialty Care Available Worldwide. Telemed e-Health. 2019;25(3):184-98.

32- van Mulligen E, de Jong PHP, Kuijper TM, van der Ven M, Appels C, Bijkerk C, et al. Gradual tapering TNF inhibitors versus conventional synthetic DMARDs after achieving controlled disease in patients with rheumatoid arthritis: first-year results of the randomised controlled TARA study. Ann Rheum Dis. 2019 Jun;78(6):746-753

33- Fernández-Ávila DG, Patino-Hernandez D, Kowalskii S, Vargas-Caselles A, Sapag AM, Cachafeiro-Vilar A, et al. Current status of the rheumatologists' workforce in Latin America: a PANLAR collaborative study. Clin Rheumatol. 2021 Jul;40(7):2913-2920

34- Gormley GJ, Steele WK, Gilliland A, Leggett P, Wright GD, Bell AL, et al. Can diagnostic triage by general practitioners or rheumatology nurses improve the positive predictive value of referrals to early arthritis clinics? Rheumatology. 2003;42(6):763-8.

35- van Vollenhoven R, Takeuchi T, Pangan AL, Friedman A, Mohamed MEF, Chen S, et al. Efficacy and Safety of Upadacitinib Monotherapy in Methotrexate-Naive Patients With Moderately-to-Severely Active 
Rheumatoid Arthritis (SELECT-EARLY): A Multicenter, Multi-Country, Randomized, Double-Blind, Active Comparator-Controlled Trial. Arthritis Rheumatol. 2020;72(10):1607-20.

36- Kaneko Y, Kato M, Tanaka Y, Inoo M, Kobayashi-Haraoka H, Amano K, et al. Tocilizumab discontinuation after attaining remission in patients with rheumatoid arthritis who were treated with tocilizumab alone or in combination with methotrexate: Results from a prospective randomised controlled study (the second year of the SURPRIS. Vol. 77, Annals of the Rheumatic Diseases. 2018. p. 1268-75.

\section{Tables}

Table 1 - Progression of the variables analized for each month. 


\begin{tabular}{|c|c|c|c|}
\hline Month/Year & $\begin{array}{c}\text { Number of appointments /1st } \\
\text { Consultation }\end{array}$ & Waiting period in days & $\begin{array}{c}\text { № of patients in the waiting } \\
\text { list }\end{array}$ \\
\hline apr/15 & 415 & 584 & 6429 \\
\hline may/15 & 551 & 594 & 6381 \\
\hline jun $/ 15$ & 384 & 597 & 6407 \\
\hline jul/15 & 614 & 593 & 6082 \\
\hline aug/15 & 674 & 611 & 5834 \\
\hline sept/15 & 622 & 581 & 5563 \\
\hline oct/15 & 600 & 569 & 5291 \\
\hline nov/15 & 657 & 565 & 5012 \\
\hline $\mathrm{dec} / 15$ & 668 & 584 & 4962 \\
\hline $\mathrm{jan} / 16$ & 406 & 516 & 4888 \\
\hline $\mathrm{feb} / 16$ & 404 & 530 & 4585 \\
\hline $\operatorname{mar} / 16$ & 769 & 560 & 4440 \\
\hline $\mathrm{apr} / 16$ & 473 & 517 & 4330 \\
\hline may/16 & 502 & 501 & 4015 \\
\hline jun/16 & 637 & 496 & 3616 \\
\hline jul/16 & 254 & 356 & 3325 \\
\hline aug/16 & 708 & 427 & 2802 \\
\hline sept/16 & 626 & 305 & 2473 \\
\hline oct/16 & 655 & 278 & 2349 \\
\hline nov/16 & 595 & 289 & 2291 \\
\hline $\mathrm{dec} / 16$ & 452 & 269 & 2375 \\
\hline jan/17 & 244 & 228 & 2010 \\
\hline $\mathrm{feb} / 17$ & 605 & 261 & 1635 \\
\hline $\operatorname{mar} / 17$ & 816 & 203 & 1279 \\
\hline $\mathrm{apr} / 17$ & 669 & 165 & 987 \\
\hline may/17 & 757 & 126 & 638 \\
\hline jun/17 & 720 & 83 & 412 \\
\hline jul/17 & 655 & 53 & 234 \\
\hline $\mathrm{aug} / 17$ & 726 & 35 & 218 \\
\hline sept/17 & 509 & 26 & 332 \\
\hline
\end{tabular}




\begin{tabular}{|c|c|c|c|}
\hline oct $/ 17$ & 437 & 40 & 138 \\
\hline nov/17 & 328 & 49 & 109 \\
\hline $\operatorname{dec} / 17$ & 177 & 66 & 62 \\
\hline jan/18 & 152 & 89 & 67 \\
\hline $\mathrm{feb} / 18$ & 163 & 34 & 114 \\
\hline $\operatorname{mar} / 18$ & 116 & 50 & 184 \\
\hline apr/18 & 281 & 32 & 116 \\
\hline may/18 & 295 & 33 & 153 \\
\hline jun/18 & 423 & 47 & 211 \\
\hline jul/18 & 492 & 31 & 62 \\
\hline aug/18 & 448 & 31 & 55 \\
\hline sept/18 & 421 & 30 & 52 \\
\hline oct/18 & 494 & 13 & 51 \\
\hline nov/18 & 459 & 6 & 54 \\
\hline $\operatorname{dec} / 18$ & 449 & 4 & 56 \\
\hline $\mathrm{jan} / 19$ & 344 & 5 & 53 \\
\hline $\mathrm{feb} / 19$ & 492 & 13 & 53 \\
\hline $\operatorname{mar} / 19$ & 454 & 6 & 53 \\
\hline apr/19 & 457 & 26 & 55 \\
\hline may/19 & 465 & 22 & 57 \\
\hline jun/19 & 462 & 9 & 69 \\
\hline jul/19 & 453 & 9 & 61 \\
\hline aug/19 & 406 & 31 & 53 \\
\hline sept/19 & 416 & 28 & 54 \\
\hline oct $/ 19$ & 408 & 21 & 79 \\
\hline nov/19 & 266 & 52 & 64 \\
\hline $\mathrm{dec} / 19$ & 342 & 25 & 73 \\
\hline Average & 465 & $28 *$ & $56,5^{*}$ \\
\hline Medium & 481,5862069 & $21 *$ & $81,45^{*}$ \\
\hline \multirow[t]{2}{*}{ Source : } & e-saude page 5 & e-saude page 7 Report & e-saude page 7 \\
\hline & Report 28 & 41 & Report 39 \\
\hline
\end{tabular}




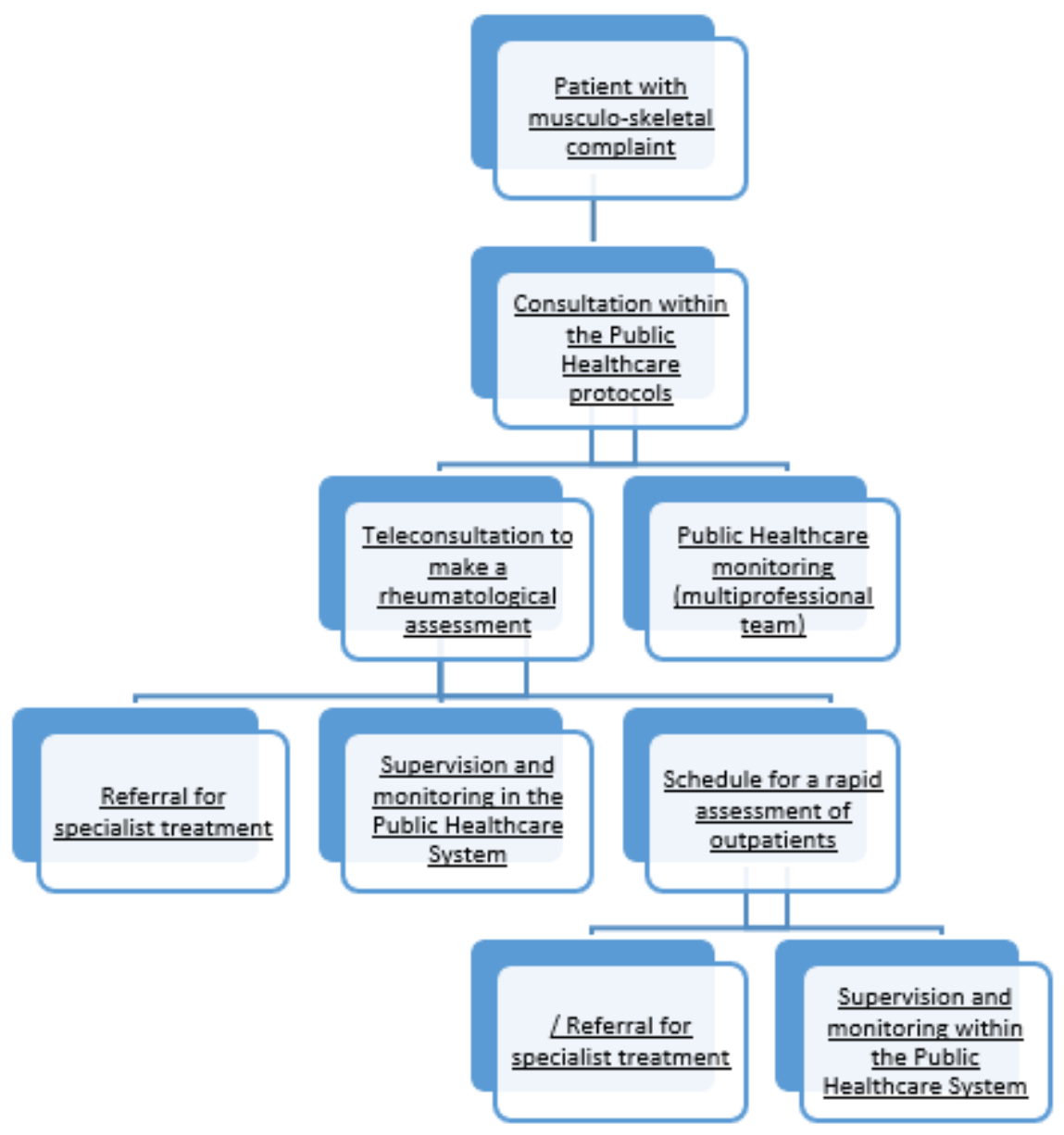

\section{Figure 1}

Flowchart of the patients requiring rheumatology

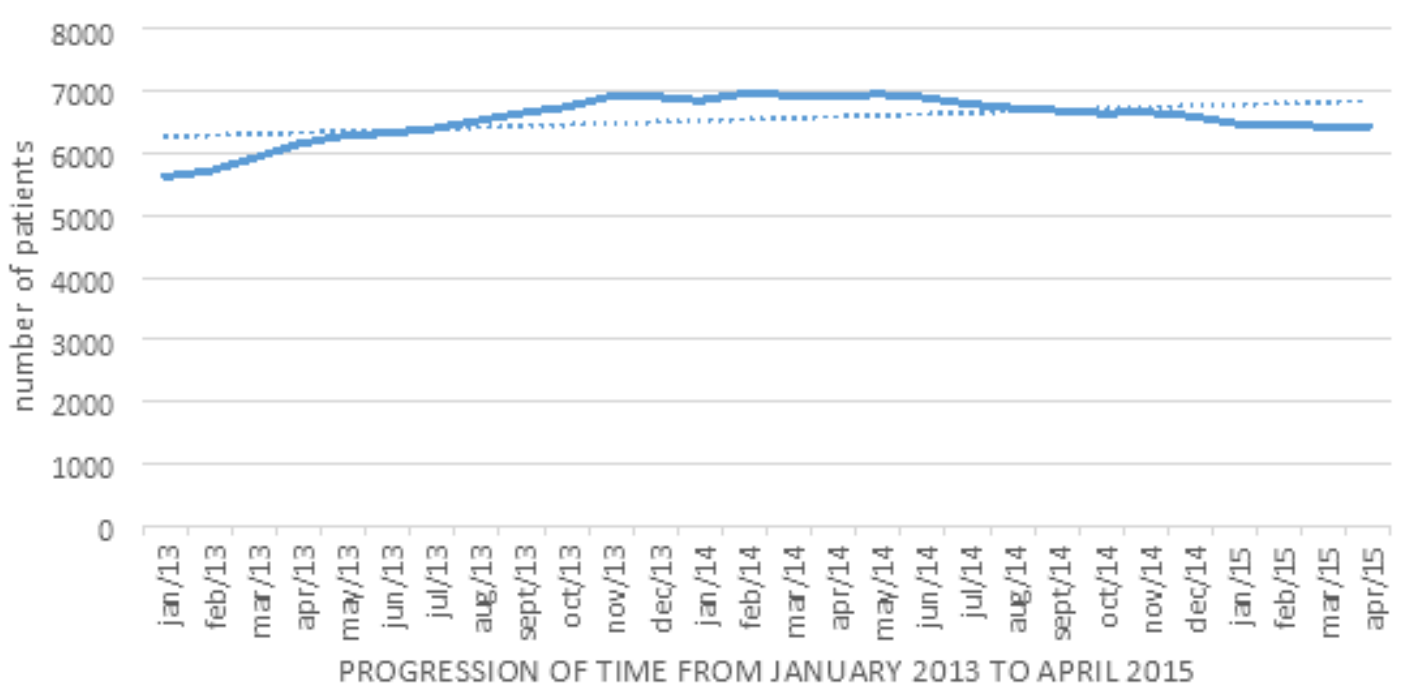

\section{Figure 2}


Number of Patients in the Waiting List for Rheumatology from January 2013 to April 2015. [Number of patients] Source : e-saude, page 7/report 39

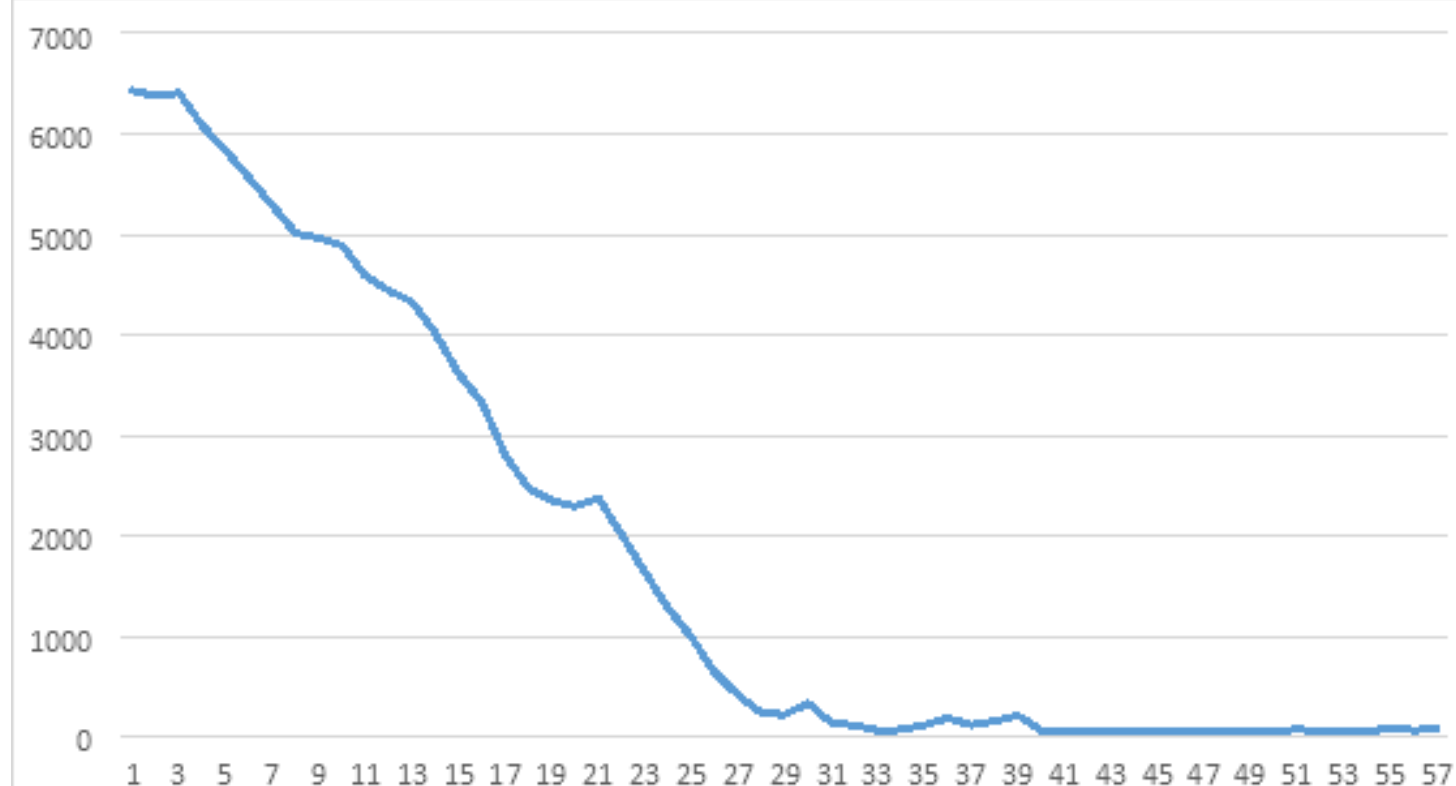

\section{Figure 3}

Number of patients for the first appointment after start screening in 57 months. Source: e-saude page 5 / report 39

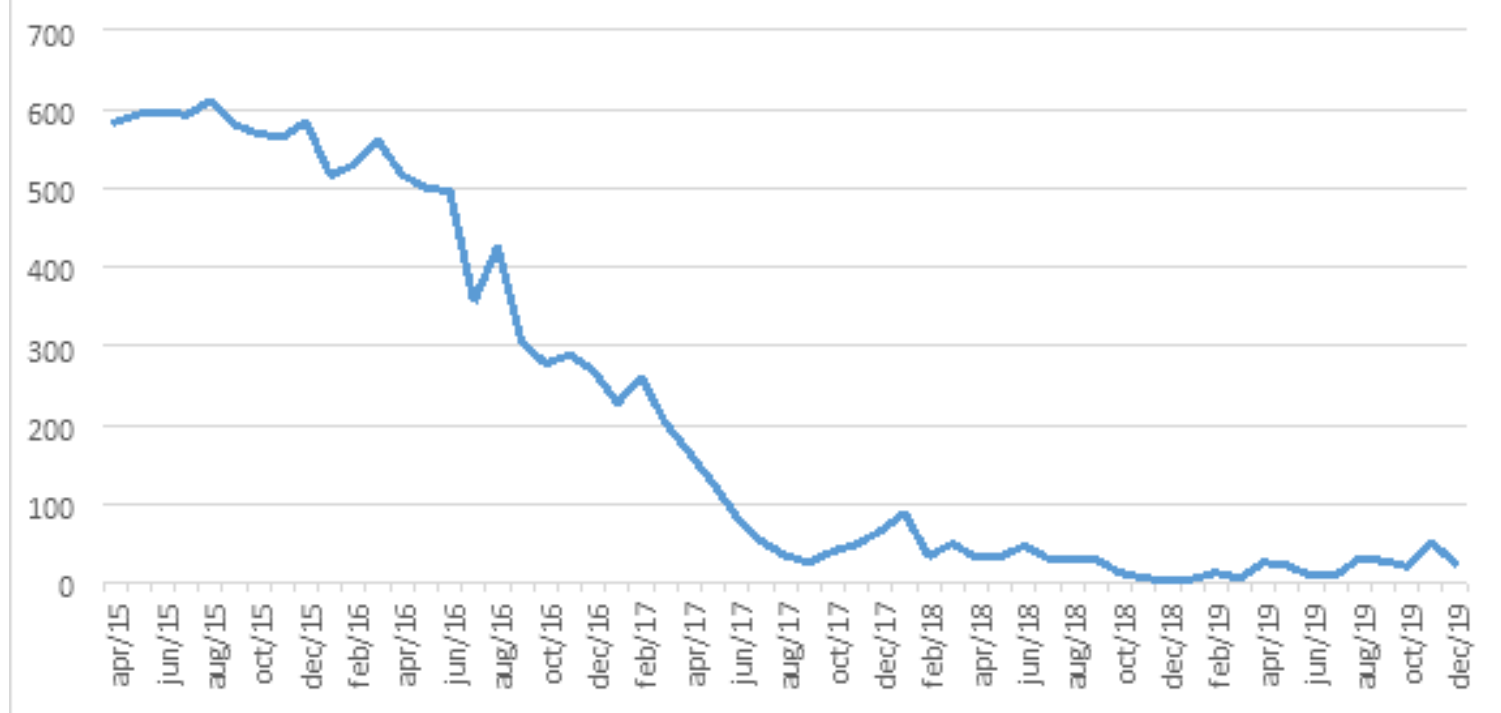

\section{Figure 4}

Waiting period in days for the First Consultation in Rheumatology. [Apr/Jun/Aug/Oct/Dec/Feb] Source: esaude page 7 / report 41 


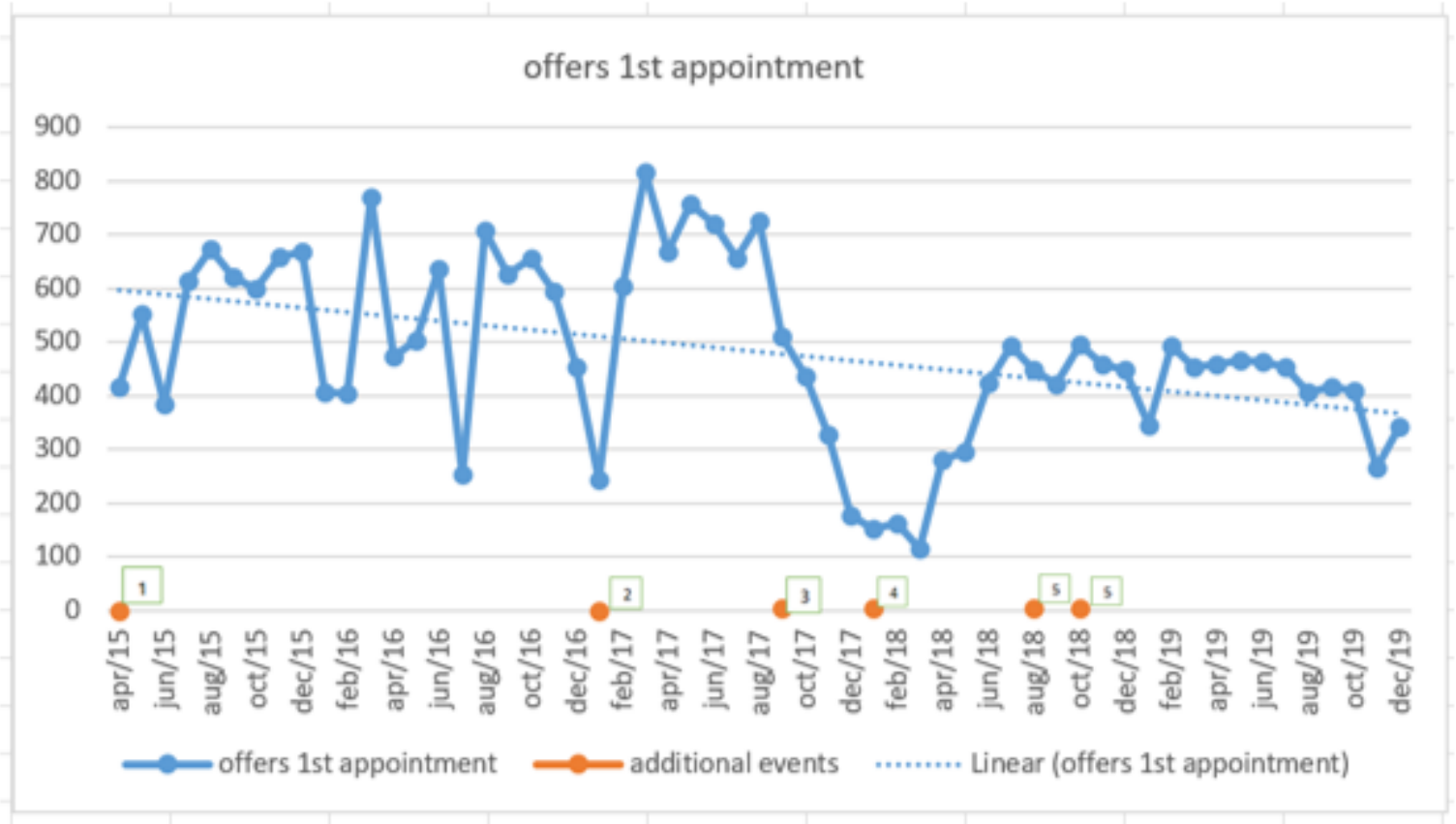

Figure 5

Appointments offered for the 1st Consultation in Rheumatology. [Number of appointments/1st Consultation/ additional events] Source: e-saude page 5 / report 28. Additional events:1- Introduction of the rheumatism screener, 2-Introduction of the 2nd rheumatism screener, 3-Beginning of the asynchronous electronic teleconsultation, 4- New Rheumatologists contracted by the service providers, 5Setting up of the Rapid Access Clinic.

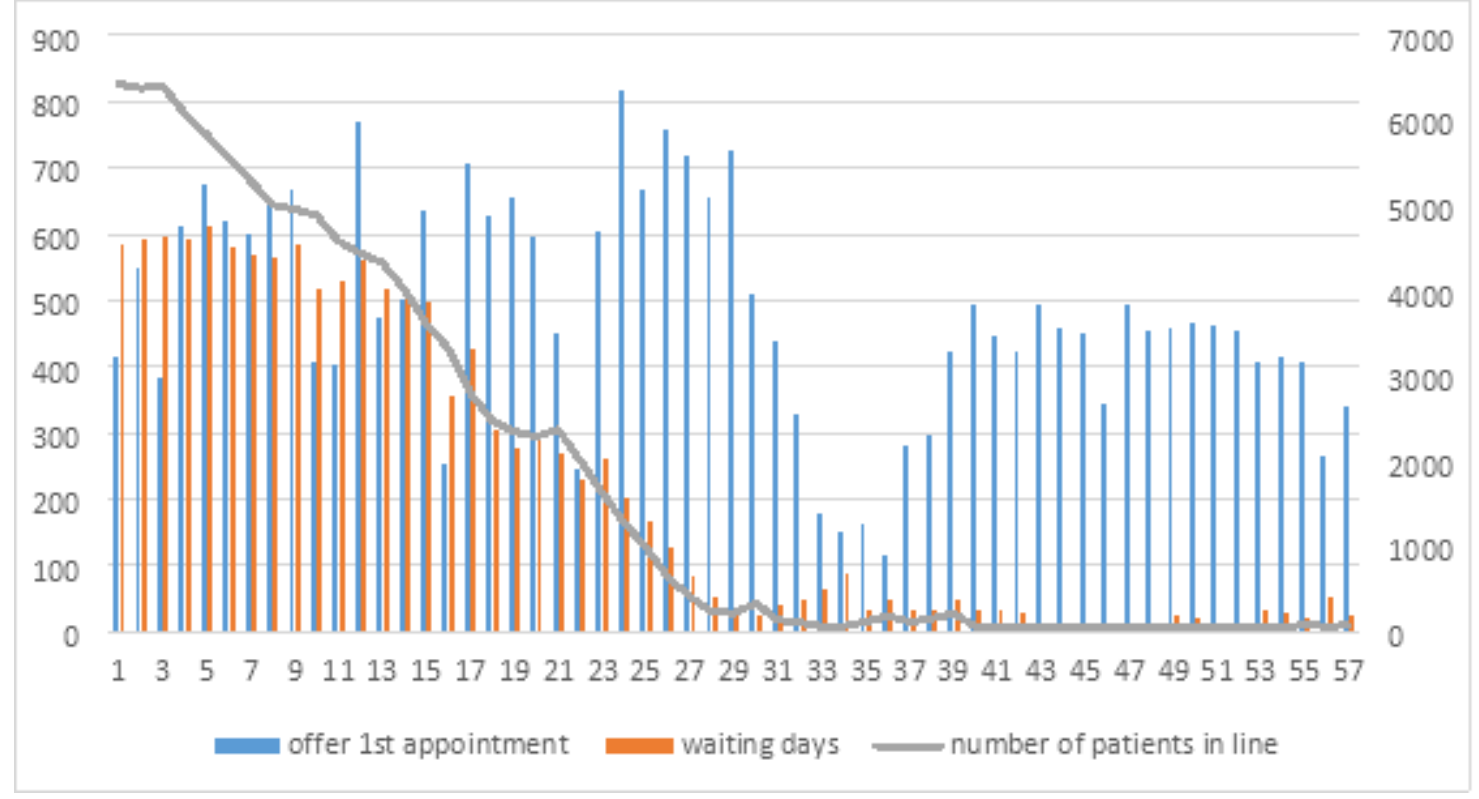

Figure 6 
Offers 1st appointments, waiting period in days and number of patients in the 57 months. [Number of appointments - 1st Consultation/ waiting period in days / Number of patients in the waiting list] Source: e-saude pages 5 and 7 / report 28, 39 and 41 